\title{
Oxidative desulfurization of diesel fuel oil using supported Fenton catalysts and assisted with ultrasonic energy
}

\author{
Roberto Flores ${ }^{1} \cdot$ Arturo Rodas $^{2} \cdot$ Raquel Gasperin $^{2}$
}

Received: 20 October 2018 / Published online: 3 July 2019

(c) The Author(s) 2019

\begin{abstract}
An ultrasound-assisted heterogeneous catalytic oxidation process was applied to eliminate sulfur from commercial diesel fuel oil. The studied variables were catalyst concentration, type of catalyst (homogeneous or heterogeneous), oxidizing agent concentration, and the application of ultrasound energy. Supported catalysts were prepared by impregnation of coal fly ash with an iron(II) sulfate aqueous solution using ultrasound energy. After drying, the catalyst was calcined at $500{ }^{\circ} \mathrm{C}$ for $4 \mathrm{~h}$. The oxidizing agent was hydrogen peroxide. Ultrasound energy was applied with a frequency of $47 \mathrm{kHz}$ and an intensity of $147 \mathrm{~W}$. Ethanol was employed for extracting the oxidized compounds from the hydrocarbon mixture. Coal fly ash and ethanol were used with the purpose of applying low-cost raw materials in chemical processes. It was found that under the studied conditions, increasing oxidizing agent concentration and the application of ultrasound energy can enhance the sulfur removal from commercial diesel fuel oil. Catalyst concentration did not play a significant role in the process. Similar results were obtained using homogeneous or heterogeneous catalyst, which is important since the heterogeneous catalyst could be recovered, reactivated, and used in many cycles.
\end{abstract}

Keywords Oxidative desulfurization $\cdot$ Diesel $\cdot$ Ultrasound energy $\cdot$ Supported catalyst $\cdot$ Low-cost raw materials

\section{Introduction}

Diesel fuel fraction is a complex mixture of hydrocarbons comprising a carbon number range of $\mathrm{C}_{9}-\mathrm{C}_{28}$, with a boiling point between 150 and $450{ }^{\circ} \mathrm{C}$, which is specially used in heavy transportation. The presence of sulfur in transportation fuels is a severe environmental concern. Once burned, the emissions not only inhibit the three-way catalyst used in the automotive industry, but also are precursors of acid rain and produce particulate matter of 2.5 micron $\left(\mathrm{PM}_{2.5}\right)$ among other sizes. The trend in environmental regulation worldwide is to cut sulfur content in diesel less than 10-15

Edited by Xiu-Qiu Peng

Roberto Flores

roberto.flores@uaem.mx

1 Facultad de Ciencias Químicas e Ingeniería, Universidad Autónoma del Estado de Morelos, Av. Universidad No. 1001, Col. Chamilpa, 62209 Cuernavaca, Morelos, Mexico

2 Gerencia de Materiales y Procesos Químicos, Instituto Nacional de Electricidad y Energías Limpias, Calle Reforma 113, Col. Palmira, 62490 Cuernavaca, Morelos, Mexico $\mathrm{ppm}_{\mathrm{w}}$ depending on the country (Hao et al. 2016; Margeta et al. 2016a, b).

The traditional method for eliminating sulfur from fuel is the hydrodesulfurization process, where light sulfur compounds (such as sulfides, thiols, and thiophenes) react with hydrogen at high pressure ( $>3 \mathrm{MPa}$ ) and temperature $\left(300-500{ }^{\circ} \mathrm{C}\right.$ ) to form hydrogen sulfide and reduce the sulfur content in the fuel. Nevertheless, recalcitrant compounds, such as dibenzothiophenes (particularly with alkyl substituents at 4 and 6 positions), barely react with hydrogen under these operating conditions and remain in the fuel. Thus, alternative technologies have been proposed, for example oxidative desulfurization, selective sulfur compound adsorption, and biological treatment (with Rhodococcus and Psuedomonas strains, or peroxidase enzymes, such as laccase, manganese, or horseradish peroxidase) among others (Bhasarkar et al. 2013, 2015a, b; Margeta et al. 2016a, b; Wu et al. 2018).

The oxidative desulfurization process proceeds at mild conditions (near atmospheric pressure and temperatures below $100{ }^{\circ} \mathrm{C}$ ) in the presence of an oxidizing agent (mainly $\mathrm{H}_{2} \mathrm{O}_{2}$ ) and different kinds of catalyst (acetic acid, formic acid, metal peroxocomplexes, amphiphilic 
catalysts, phosphotungstic acid, $\mathrm{K}_{2} \mathrm{FeO}_{4}, \mathrm{Na}_{2} \mathrm{MoO}_{4}$, $\left[\left(\mathrm{C}_{4} \mathrm{H}_{9}\right)_{4} \mathrm{~N}\right]_{6} \mathrm{Mo}_{7} \mathrm{O}_{24}$, dialkylpiperidinium tetrachloroferrate). In this way, dibenzothiophene-like compounds are oxidized to sulfones and sulfoxides as is illustrated for dibenzothiophene and 4,6-dimethyl dibenzothiophene in Scheme 1. Due to their higher polar characteristics, they are separated from the fuel by extraction or adsorption processes, with either liquid or solid agents (Bhasarkar et al. 2013; Farzin-Nejad and Miran-Beigi 2015; Hao et al. 2016; Jiang et al. 2014; Julião et al. 2015; Kairbekov et al. 2018; Margeta et al. 2016a, b; Liu et al. 2008; Lü et al. 2014a, b). In the liquid-liquid extraction process, different kinds of solvent, such as acetone, acetonitrile, dimethyl sulfoxide, $N$-methyl-2-pyrrolidone, $N, N$-dimethylformamide, deep eutectic solvents, and ionic liquids (with an asymmetrically substituted cation, e.g., imidazolium, pyrrolidinium, ammonium, phosphonium, and a halogen-based anion, such as octyl-3-methylimidazolium hydrogen sulfate, 1-butyl-3-methylimidazolium hexafluorophosphate, and 1-n-octyl-3-methylimidazolium tetrafluoroborate), are used with different results (Bhasarkar et al. 2013; Hao et al. 2016; Jiang et al. 2014; Julião et al. 2015; Lü et al. 2014a, b; Safa et al. 2017).

Since mass transfer of the reactants between phases limits these systems, phase transfer agents such as quaternary ammonium salts are added to enhance the rate of reaction (Bhasarkar et al. 2013; de Luna et al. 2018). Another alternative is to apply ultrasound energy in the process in order to improve its overall efficiency. Ultrasound favors the generation of oxidizing radicals due to the dissociation of gas and vapor molecules during the transient collapse of the cavitation bubbles, and enhances the mass transfer between the two liquid phases due to strong cavitation activity, derived from the implosion of microbubbles which creates strong convection through microstreaming, microturbulence, and microjets. Cavitation is mainly the nucleation, growth, and implosive collapse of tiny gas bubbles that creates intense energy concentration on an extremely small spatial and temporal scale (Bhasarkar et al. 2013, 2015a, b; Margeta et al. 2016a, b).

Catalytic oxidation of sulfur compounds is traditionally achieved with Fenton-like reagents, such as phosphotungstic acid and copper/iron salts. These compounds are dissolved in water and then mixed with the hydrocarbon. After the reaction, the aqueous phase is separated and the homogeneous catalyst is lost in this solution. Recently, in order to avoid this lost, supported catalysts have been prepared and tested in the sulfur compound oxidation process. In this way, the catalyst is easily recovered by filtration and, if necessary, reactivated by calcination (Jiang et al. 2018; Julião et al. 2015; Liu et al. 2008; Rafiee et al. 2016; Sun et al. 2018; Tomskii et al. 2017; Yang et al. 2017; Yu et al. 2018a, b).

In the present work, supported Fenton-like catalysts were prepared by impregnating an iron salt onto coal fly ash. After calcination, iron species $\left(\mathrm{Fe}^{2+}\right.$ and $\left.\mathrm{Fe}^{3+}\right)$ are formed over the surface of the support. In addition, distilled ethanol, bought in a local drugstore (obtained from a sugar mill without further purification), was used to remove the oxidized species from the hydrocarbon mixture. The reason of applying coal fly ash and distilled ethanol is to use low-cost raw materials in chemical processes. Low-cost raw materials must be abundant and require little processing, or being a by-product from a waste industry (Bailey et al. 1999). Coal fly ash is unwanted mineral residue coming from coal power plants during the generation of steam. The production of these ashes is very extensive, and there is a worldwide environmental concern related to their final disposal.
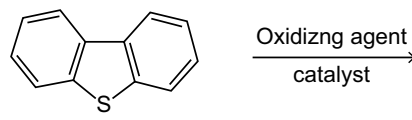

Benzothiophene

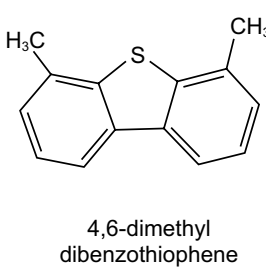

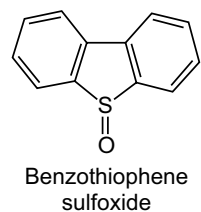

$\underset{\text { catalyst }}{\stackrel{\text { Oxidizng agent }}{\longrightarrow}}$ sulfoxide
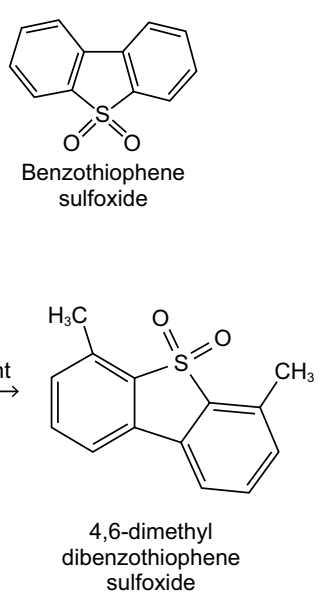

Scheme 1 Catalytic oxidation of dibenzothiophene-like compounds 


\section{Experimental}

\subsection{Materials and reactants}

Hydrogen peroxide solution (30 wt $\%$ ) and iron(II) sulfate ( $\mathrm{FeSO}_{4} \cdot 7 \mathrm{H}_{2} \mathrm{O}$, reactive grade) were purchased from J. T. Baker and used as received. Distilled ethanol (from sugarcane) was bought in a local drugstore and used as received. Diesel fuel oil was purchased in a gas station and used as received. Coal fly ash was obtained from a coal thermal power station located in the North of Mexico that operates with subbituminous Mexican coal; it was washed several times with distilled water to remove all soluble compounds, and then, it was dried at $120{ }^{\circ} \mathrm{C}$ overnight and stored at $70{ }^{\circ} \mathrm{C}$ to avoid humidification.

\subsection{Ultrasonic energy generator}

The ultrasonic energy was applied at different experimental stages using a Cole Parmer 8890R-MTH ultrasonic bath with a frequency of $47 \mathrm{kHz}$ and an intensity of $147 \mathrm{~W}$.

\subsection{Catalyst preparation}

Catalysts were prepared through supporting the metal ions by the incipient impregnation method and applying ultrasonic energy. In this process, $6.0 \mathrm{~g}$ of $\mathrm{FeSO}_{4} \cdot 7 \mathrm{H}_{2} \mathrm{O}$ was dissolved in a beaker containing $20 \mathrm{~mL}$ of distilled water. Next, $10 \mathrm{~g}$ of fly ash was added to the aqueous solution, and ultrasonic energy was applied for an hour. Then, the beaker was agitated at $120 \mathrm{rpm}$ and $70{ }^{\circ} \mathrm{C}$ until the water was evaporated. After the impregnation, the sample was dried at $110{ }^{\circ} \mathrm{C}$ overnight, and then, it was calcined at $500{ }^{\circ} \mathrm{C}$ for $4 \mathrm{~h}$. The objective of applying ultrasonic energy was to reduce the particle size and enhance the catalytic activity as has been demonstrated in other studies (Flores et al. 2018a, b).

\subsection{Experimental procedure}

The experimental procedure consisted of preparing aqueous solutions of distilled ethanol with $\mathrm{H}_{2} \mathrm{O}_{2}$, at ethanol concentrations of $3 \mathrm{wt} \%$ and $10 \mathrm{wt} \%$, and catalyst (homogeneous or heterogeneous), at concentrations of 20 and $40 \mathrm{mM}$. For the experiments with homogeneous catalyst, $\mathrm{FeSO}_{4} \cdot 7 \mathrm{H}_{2} \mathrm{O}$ was used as catalyst, which is easily dissolved in the aqueous solution. Twenty milliliters of this solution was added to $20 \mathrm{~mL}$ of diesel fuel oil and homogenized using a mechanical stirrer. Then, the reactant mixture was placed inside the ultrasonic bath, and ultrasonic energy was applied for $20 \mathrm{~min}$. Also, other experiments were performed without using ultrasonic energy, and the mixture was mechanically mixed during the same period of time. After the reaction stage, separation into polar and nonpolar phases occurred. After that, the diesel fuel oil samples were analyzed to determine the sulfur content. All the experiments were conducted at room temperature.

\subsection{Analytical methods}

Diesel fuel oil samples were analyzed in a LECO Sulfur Analyzer Model S-144DR according to the ASTM D 155203 method to determine the sulfur content before and after the experimental treatments.

Coal fly ash was characterized according to the ASTMD3682-01 method to determine the major element compositions.

Total iron and iron(II) cation were quantified by ferrozine method and 1,10-phenanthroline method, respectively. Both are spectrophotometric Hach methods (Viollier et al. 2000).

\subsection{Experimental design}

The conditions to analyze the effect of the studied variables in the sulfur reduction were implemented using a full $2^{4}$ factorial design. Experimental conditions for low and high levels are listed in Table 1. Randomization was used in order to obtain a random distribution of unknown systematic errors. The factors included in the analysis are A: catalyst concentration; B: type of catalyst; $\mathrm{C}: \mathrm{H}_{2} \mathrm{O}_{2}$ concentration; D: agitation type.

\section{Results}

\subsection{Material characterizations}

Sulfur content in the commercial diesel was determined according to the ASTM D 1552-03 method, and the sulfur content was $595 \mathrm{ppm}_{\mathrm{w}}$.

Metal content in the original coal fly ash was determined according to ASTM D3682-01, and the main results

Table 1 Interval of the parameters introduced in the strategy of the $2^{4}$ complete factorial design

\begin{tabular}{lll}
\hline Factors & Level \\
\cline { 2 - 3 } & Low (-) & High (+) \\
\hline $\begin{array}{l}\text { A: Catalyst concentration, } \\
\mathrm{mM}\end{array}$ & 20 & 40 \\
B: Type of catalyst & Homogeneous & Heterogeneous \\
C: $\mathrm{H}_{2} \mathrm{O}_{2}$ concentration, wt\% & 3 & 10 \\
D: Agitation type & Mechanical stirring & Ultrasonic energy
\end{tabular}


were as follows: $\mathrm{Si}(26 \mathrm{wt} \%), \mathrm{Al}(14 \mathrm{wt} \%), \mathrm{Ca}(2 \mathrm{wt} \%), \mathrm{K}$ (1.09 wt \%), Ti (1 wt\%), Na (0.5 wt \%), Mg (0.5 wt \%), Fe (0.06 wt \%), Cr (0.02 wt \%), Mn (0.014 wt \%), Pb (0 wt \%).

Table 2 The design matrix and analysis results from the $2^{4}$ complete factorial design for desulfurization of diesel

\begin{tabular}{lllll}
\hline Factors & & & & \multicolumn{2}{l}{ Sulfur reduction, ${ }^{\mathrm{a}}$} \\
\hline A & B & C & D & \\
\hline- & - & - & - & $26.11(12)$ \\
+ & - & - & - & $21.07(2)$ \\
- & + & - & - & $19.40(15)$ \\
+ & + & - & - & $17.72(1)$ \\
- & - & + & - & $29.47(7)$ \\
+ & - & + & - & $27.79(13)$ \\
- & + & + & - & $22.75(8)$ \\
+ & + & + & - & $31.15(14)$ \\
- & - & - & + & $29.47(16)$ \\
+ & - & - & + & $27.79(3)$ \\
- & + & - & + & $22.75(10)$ \\
+ & + & - & + & $29.47(9)$ \\
- & - & + & + & $34.51(4)$ \\
+ & - & + & + & $31.15(5)$ \\
- & + & + & + & $24.43(11)$ \\
+ & + & + & + & $37.87(6)$ \\
\hline
\end{tabular}

${ }^{a}$ Values in parentheses indicate the randomized order in which the tests were run
The maximum amount of immobilized $\mathrm{Fe}^{3+}$ was evaluated by dissolving $0.1 \mathrm{~g}$ of catalyst following the standardized digestion procedure of ASTM-D3682-01. Then, total iron and ferrous iron were analyzed by the FerroZine method and 1,10-phenanthroline method, respectively. The amount of immobilized iron was 8.212 and $0.375 \mathrm{mg}$ for $\mathrm{Fe}^{3+}$ and $\mathrm{Fe}^{2+}$ species, respectively.

\subsection{Statistical analysis}

Table 2 gives the design matrix for the factorial experimental design, the obtained sulfur reduction, and, in parenthesis, the order in which the experiments were conducted. Experimental results were evaluated using Minitab software. These results were first analyzed by a Pareto diagram with a confidence level of 5\%, to determine which factors and/or interaction may be significant in the elimination of sulfur from diesel. This analysis produced a bar chart shown in Fig. 1. In this chart, the bar lengths are proportional to the absolute value of the estimated effects. The bars that exceed a reference line, at 12.71, are significant values with respect to the response. Therefore, this analysis gives that the factors affecting the sulfur reduction are the concentration of the oxidizing agent, and the application or not of ultrasonic energy. In addition, a strong interaction between the type of catalyst (homogeneous or heterogeneous) and its concentration is observed, even though these factors are not significant alone.

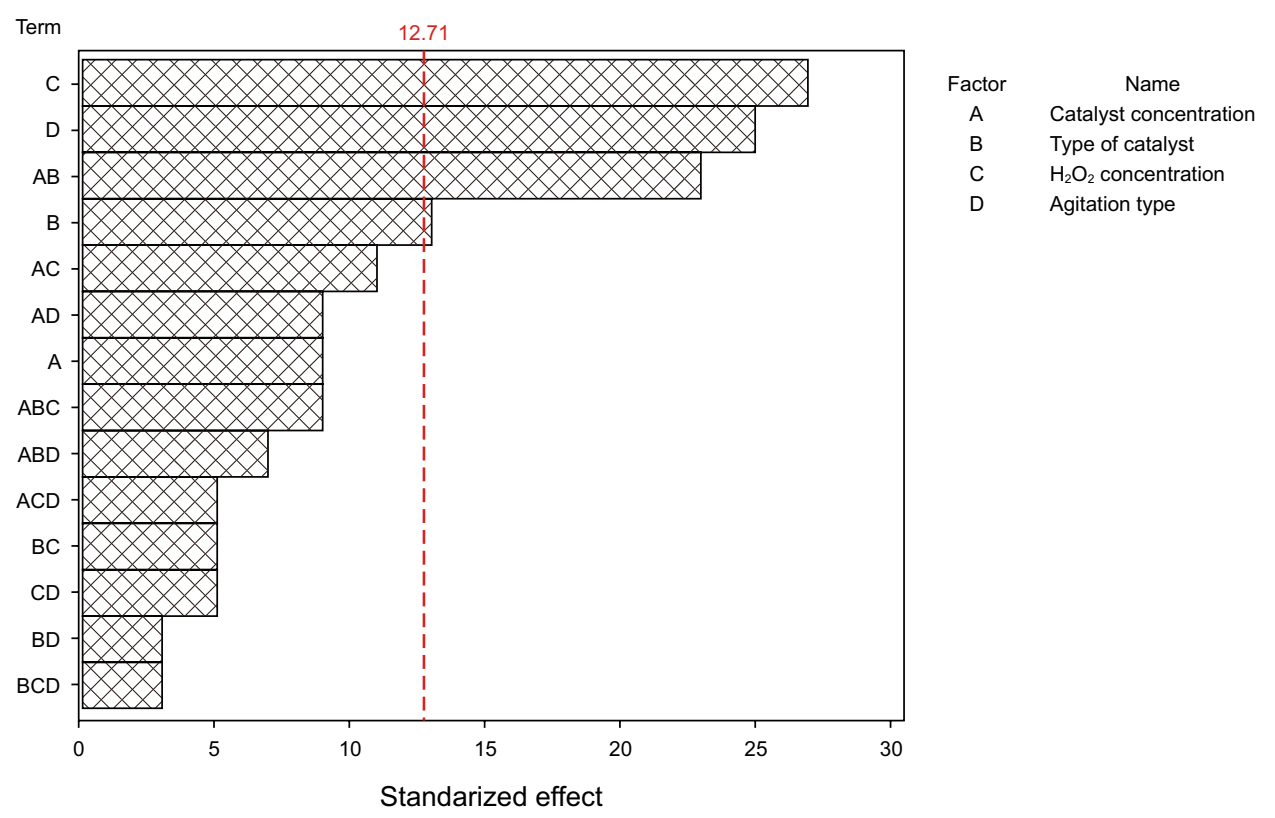

Fig. 1 Pareto chart of the standardized effects obtained for the factorial design optimization of the variables a catalyst concentration, $\mathbf{b}$ type of catalyst, $\mathbf{c} \mathrm{H}_{2} \mathrm{O}_{2}$ concentration, $\mathbf{d}$ agitation type on the sulfur reduction, and their interactions. The vertical line indicates a confidence limit of $95 \%$ 


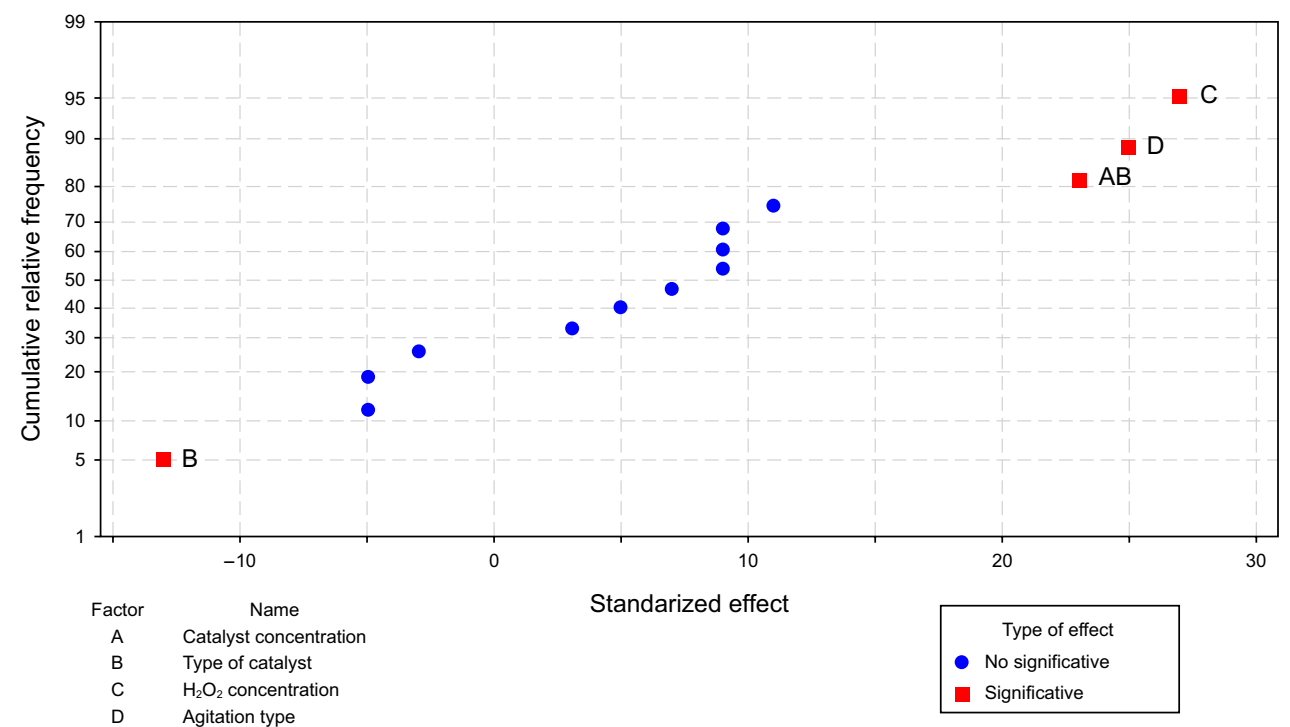

Fig. 2 Normal probability plot for the effects of a catalyst concentration, $\mathbf{b}$ type of catalyst, $\mathbf{c} \mathrm{H}_{2} \mathrm{O}_{2}$ concentration, and $\mathbf{d}$ agitation type on the sulfur reduction

The graph in Fig. 2 shows the accumulated frequency as a function of the factors and their interactions. Results are similar to the Pareto diagram: Concentration of the oxidizing agent and the application of ultrasonic energy are the factors that have the major influence in the reduction in sulfur in the diesel samples. Some influence of the type of catalyst is also observed, and it is confirmed that the interaction between the type of catalyst and its concentration is relevant.

Figure 3 displays the interaction plots of the studied factors for the sulfur reduction. It is observed that the main factors that are significant (concentration of the oxidizing agent and application of ultrasonic energy) do not interact with the other factors. Again, the only observed interaction is between the type of catalyst and its concentration. Results from the Pareto diagram and the accumulated frequency of the effects graph are confirmed in the Table of Analysis of Variance shown in Table 3. The concentration of oxidizing agent, the application of ultrasonic energy, and the interaction between the type of catalyst and its concentration have a $P$ value less than 0.05 , so they are significant in the process of desulfurization of diesel.

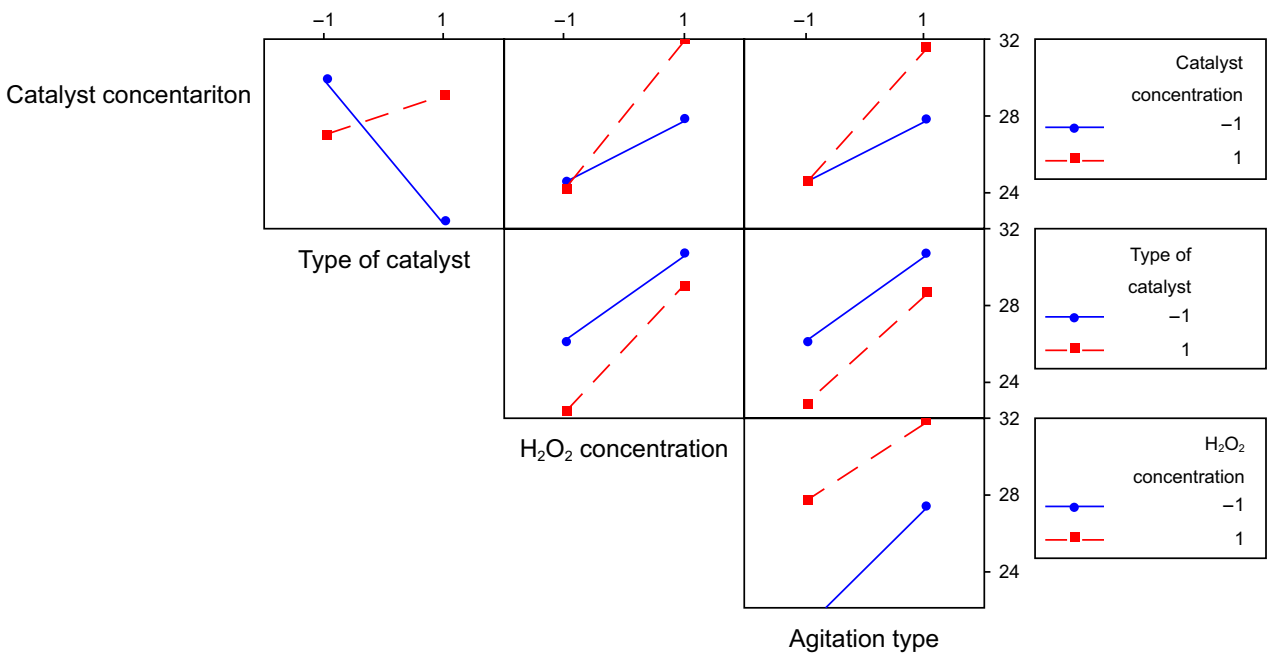

Fig. 3 Influence of the interaction of the factors on the sulfur reduction 
Table 3 Results of the analysis of variance (ANOVA) from the factorial design test for desulfurization of diesel

\begin{tabular}{lrccrl}
\hline Source & $\begin{array}{l}\text { Sum of } \\
\text { squares }\end{array}$ & $\begin{array}{l}\text { Degrees } \\
\text { of free- } \\
\text { dom }\end{array}$ & Mean squares & $F$ ratio & $p$ Value \\
\hline $\mathrm{A}$ & 14.276 & 1 & 14.276 & 2.45 & 0.178 \\
$\mathrm{~B}$ & 29.785 & 1 & 29.785 & 5.12 & 0.073 \\
$\mathrm{C}$ & 128.482 & 1 & 128.482 & 22.09 & $0.005^{*}$ \\
$\mathrm{D}$ & 110.152 & 1 & 110.152 & 18.94 & $0.007^{*}$ \\
$\mathrm{~A} \times \mathrm{B}$ & 93.233 & 1 & 93.233 & 16.03 & $0.010^{*}$ \\
$\mathrm{~A} \times \mathrm{C}$ & 21.326 & 1 & 21.326 & 3.67 & 0.114 \\
$\mathrm{~A} \times \mathrm{D}$ & 14.276 & 1 & 14.276 & 2.45 & 0.178 \\
$\mathrm{~B} \times \mathrm{C}$ & 4.406 & 1 & 4.406 & 0.76 & 0.424 \\
$\mathrm{~B} \times \mathrm{D}$ & 1.586 & 1 & 1.586 & 0.27 & 0.624 \\
$\mathrm{C} \times \mathrm{D}$ & 4.406 & 1 & 4.406 & 0.76 & 0.424 \\
Error & 29.081 & 5 & 5.816 & & \\
Total & 451.009 & 15 & & & \\
\hline
\end{tabular}

*Significant factors at $p<0.05$

$\mathrm{H}_{2} \mathrm{O}_{2}$ concentration (C), the agitation type (D), and the interaction between catalyst concentration and type of catalyst $(\mathrm{A} \times \mathrm{B})$ are statistically significant

\section{Discussions}

\subsection{Effect of catalyst concentration}

Experiments were achieved at two different catalyst concentrations: 20 and $40 \mathrm{mM}$. The effect on the overall process is presented in Fig. 4. It can be observed that increasing the amount of catalyst barely improves in the efficiency of the process. The main role of the catalyst in the process is the formation of the oxidizing radical $\mathrm{HO}^{\circ}$, which later would react with sulfur species to form sulfoxides and sulfones. For this reason, it could be considered that there is another controlling step in the process, such as the oxidation of the sulfur species, or the mass transfer between phases of the oxidized species. Li et al. (2016) explain the oxidative desulfurization process based on electron density and Fukui functions of sulfur species once the oxidizing agent is formed. They state that the steric hindrance of methyl groups plays an important role in the selectivity of the oxidation of sulfur species; however, there is not a general tendency, and the selectivity strongly depends on the type of catalysts. For the case of iron-based catalyst, they remark that the oxidative desulfurization tends to be a radical attack reaction.

\subsection{Effect of type of catalyst}

Figure 4 shows a difference in the performance between the homogeneous and heterogeneous catalyst even though in the statistical analysis this was not significant. In general, the homogeneous catalyst gives higher sulfur reduction than the heterogeneous one. This may be explained in two ways. First, some diffusion resistance of the oxidizing agent may exist before it reaches the active sites of the catalyst, so the overall process becomes slower. Second, and perhaps the most important reason, is the presence of $\mathrm{Fe}^{3+} / \mathrm{Fe}^{2+}$ as an active site in the heterogeneous catalyst. Previous reports have shown that the strongest oxidizing radical ( $\left.\mathrm{HO}^{\circ}\right)$ is formed by the decomposition of the $\mathrm{H}_{2} \mathrm{O}_{2}$ over the $\mathrm{Fe}^{2+}$. But then, this radical interacts with the $\mathrm{Fe}^{3+} / \mathrm{Fe}^{2+}$ species in a reaction mechanism to form less effective oxidizing radicals (such as $\mathrm{HO}_{2}^{-}$and $\mathrm{O}_{2}^{--}$) before it reacts with the sulfur compounds (Giannakis et al. 2017). Therefore, the initial presence of $\mathrm{Fe}^{3+}$ in the catalyst may accelerate the evolution of this side reaction mechanism. The effect may be minimal because the application of ultrasonic energy implies a drastic change in the overall process as it will be explained later.

\subsection{Effect of oxidizing agent concentration}

The effect of the concentration of $\mathrm{H}_{2} \mathrm{O}_{2}$ was studied at $3 \mathrm{wt} \%$ and $10 \mathrm{wt} \%$. Figure 4 shows that, at the studied levels, increasing the presence of $\mathrm{H}_{2} \mathrm{O}_{2}$ in the system favors the reduction in sulfur in the diesel even though other studies

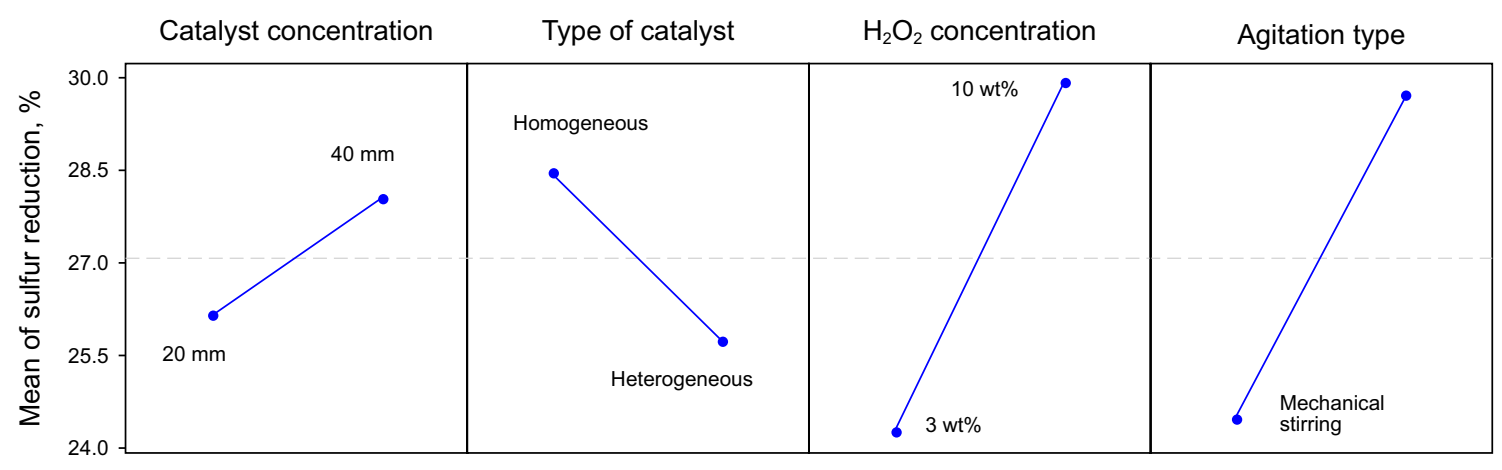

Fig. 4 Influence of the single factors on the sulfur reduction 
have proved that higher concentration of oxidizing agent does not improve and/or inhibit the overall performance (Hao et al. 2016; Julião et al. 2015; Yang et al. 2017; Yu et al. 2018a, b). This was also confirmed in the statistical analysis previously described in the Table of Analysis of Variance (Table 3), the Pareto diagram (Fig. 1), and the normal plot of standardized effects (Fig. 2). Increasing the amount of $\mathrm{H}_{2} \mathrm{O}_{2}$ provides more oxidizing radicals $\mathrm{HO}^{\circ}$, so the oxidation rate of the sulfur compounds may be enhanced. However, a large excess of the oxidizing agent does not improve the oxidation rate because it would form less oxidizing species as it has been explained in other works (Buxton et al. 1988; Changotra et al. 2019; Giannakis et al. 2017):

$$
\begin{aligned}
& \mathrm{HO}+\mathrm{H}_{2} \mathrm{O}_{2} \rightarrow \mathrm{HO}_{2}^{-}+\mathrm{H}_{2} \mathrm{O} \\
& \mathrm{H}_{2} \mathrm{O}_{2}+\mathrm{OH}^{-} \leftrightarrow \mathrm{HO}_{2}^{-}+\mathrm{H}_{2} \mathrm{O} \\
& \mathrm{HO}+\mathrm{HO}_{2}^{-} \rightarrow \mathrm{O}_{2}^{--}+\mathrm{H}_{2} \mathrm{O} \\
& \mathrm{HO}+\mathrm{OH}^{--} \rightarrow \mathrm{O}^{--}+\mathrm{H}_{2} \mathrm{O} \\
& \mathrm{O}^{--}+\mathrm{H}_{2} \mathrm{O}_{2} \rightarrow \mathrm{O}_{2}^{--}+\mathrm{H}_{2} \mathrm{O} \\
& \mathrm{O}^{--}+\mathrm{HO}_{2}^{-} \rightarrow \mathrm{O}_{2}^{--}+\mathrm{H}_{2} \mathrm{O} \\
& \mathrm{HO}_{2}^{-}+\mathrm{HO} \rightarrow \mathrm{H}_{2} \mathrm{O}+\mathrm{O}_{2}
\end{aligned}
$$

In addition, if there is a large excess of these oxidizing species some inhibition of the catalyst may occur due to side reactions, and the formation of complex species with the $\mathrm{Fe}^{2+} / \mathrm{Fe}^{3+}$ ions as has been previously reported (Buxton et al. 1988; Changotra et al. 2019; Giannakis et al. 2017):

$$
\begin{aligned}
& \mathrm{Fe}^{2+}+\mathrm{HO}_{2} \leftrightarrow \mathrm{Fe}^{3+}\left(\mathrm{HO}_{2}\right)^{2+} \\
& \mathrm{Fe}^{2+}+\mathrm{O}_{2}^{--}+\mathrm{H}^{+} \rightarrow \mathrm{Fe}^{3+}\left(\mathrm{HO}_{2}\right)^{2+} \\
& \mathrm{Fe}^{3+}+\mathrm{H}_{2} \mathrm{O}_{2} \leftrightarrow \mathrm{Fe}^{3+}\left(\mathrm{HO}_{2}\right)^{2+}+\mathrm{H}^{+} \\
& \mathrm{Fe}^{3+}(\mathrm{OH})^{2+}+\mathrm{H}_{2} \mathrm{O}_{2} \leftrightarrow \mathrm{Fe}^{3+}(\mathrm{OH})\left(\mathrm{HO}_{2}\right)^{+}+\mathrm{H}^{+}
\end{aligned}
$$

\subsection{Effect of ultrasound energy}

The application of ultrasound energy improved the removal of sulfur compounds from the diesel as is shown in Fig. 4 and confirmed in the statistical analysis. Two main contributions may be assigned to this effect. First, a physical issue since the cavitation causes microturbulence facilitating, in this way, the mass transfer phenomena of the oxidized species in the extraction step (Bhasarkar et al. 2015b; Deshpande et al. 2005). Second, a chemical issue because many reactions happen during cavitation through thermal dissociation of gas and solvent vapor at extreme temperature and pressure conditions reached in the bubble during transient collapse (Bhasarkar et al. 2015b; Dai et al. 2011; Margeta et al. 2016a, b). The main reaction that would enhance the oxidation process is the following:

$\mathrm{H}_{2} \mathrm{O}_{2} \rightarrow 2 \mathrm{HO}^{\circ}$

$\mathrm{H}_{2} \mathrm{O} \rightarrow \mathrm{H}^{+}+\mathrm{HO}^{\circ}$

$\mathrm{RR}^{\prime} \rightarrow \cdot \mathrm{R}+\mathrm{R}^{\prime}$

In addition, some of the side products in the oxidizing agent decomposition react again through the sonication to produce more $\mathrm{HO}^{\circ}$. In this way, there are more oxidizing radicals in the system (coming from the decomposition of water and for the improvement in its production from $\mathrm{H}_{2} \mathrm{O}_{2}$ ), and the sulfur compounds form excited species that react more easily with these radicals.

\subsection{General remarks}

Experimental results show similar yields compared to other works that use the heterogeneous catalytic oxidative desulfurization approach under the same experimental conditions: 20 min of reaction time, and room temperature. Most of the references report a sulfur removal between $25 \%$ and $40 \%$ after 20 min of reaction time at room temperature, using different types of metallic catalyst and organic and ionic liquid solvents (Bhasarkar et al. 2015b; Hao et al. 2016; Jiang et al. 2018; Lü et al. 2014a; Margeta et al. 2016a; Safa et al. 2017; Yang et al. 2017; Yu et al. 2018b; Zhu et al. 2015). In the present work, the low-cost raw materials (coal fly ash and distilled ethanol) in the chemical processes approach were used in order to reduce operating cost. Further experiments at higher temperatures and longer reaction times have to be performed in order to validate this approach as an attractive alternative to remove sulfur from diesel fuel oil. Also, recovery and reactivation of the catalyst must be studied to determine the feasibility of using it in many catalytic cycles.

\section{Conclusions}

Sulfur removal from commercial diesel was achieved using an ultrasound-assisted oxidative process with a supported Fenton-like catalyst. Application of ultrasound energy enhanced the overall efficiency process because it facilitates the mass transfer of oxidized compounds during the extraction stage, produces more oxidizing radicals $\mathrm{HO}^{\circ}$, and may excite the sulfur compounds in the diesel. Increasing the oxidizing agent concentration from $3 \mathrm{wt} \%$ to $10 \mathrm{wt} \%$ improved the sulfur removal. Larger amounts of this agent 
may not be beneficial in the process because the limiting factor is the sulfur compounds in the diesel, and also some inhibition of the catalyst may occur due to side reactions with oxidative species. No statistical difference was found in the use of homogeneous or heterogeneous catalysts; it could be attractive since the heterogeneous catalyst is easily recovered and would be used in many cycles. Finally, it was proved that low-cost raw materials can be used in the process with useful results, reducing in this way the operating costs.

Open Access This article is distributed under the terms of the Creative Commons Attribution 4.0 International License (http://creativeco mmons.org/licenses/by/4.0/), which permits unrestricted use, distribution, and reproduction in any medium, provided you give appropriate credit to the original author(s) and the source, provide a link to the Creative Commons license, and indicate if changes were made.

\section{References}

ASTM D3682-01. Standard Test Method for Major and Minor Elements in Combustion Residues from Coal Utilization Processes.

ASTM D1552-03. Standard Test Method for Sulfur in Petroleum Products (High-Temperature Method).

Bailey SE, Olin TJ, Bricka RM, Adrian DD. A review of potentially low-cost sorbents for heavy metals. Water Res. 1999;33:2469-79. https://doi.org/10.1016/S0043-1354(98)00475-8.

Bhasarkar JB, Chakma S, Moholkar VS. Mechanistic features of oxidative desulfurization using sono-Fenton-peracetic acid (ultrasound $/ \mathrm{Fe}^{2+}-\mathrm{CH}_{3} \mathrm{COOH}-\mathrm{H}_{2} \mathrm{O}_{2}$ ) system. Ind Eng Chem Res. 2013;52:9038-47. https://doi.org/10.1021/ie400879j.

Bhasarkar JB, Chakma S, Moholkar VS. Investigations in physical mechanism of the oxidative desulfurization process assisted simultaneously by phase transfer agent and ultrasound. Ultrason Sonochem. 2015a;24:98-106. https://doi.org/10.1016/j.ultso nch.2014.11.008.

Bhasarkar J, Borah AJ, Goswami P, Moholkar VS. Mechanistic analysis of ultrasound assisted enzymatic desulfurization of liquid fuels using horseradish peroxidase. Bioresour Technol. 2015b;196:8898. https://doi.org/10.1016/j.biortech.2015.07.063.

Buxton GV, Greenstock CL, Helman WP, Ross AB. Critical Review of rate constants for reactions of hydrated electrons, hydrogen atoms and hydroxyl radicals ( $\mathrm{OH} / \mathrm{O}$ - in aqueous solution. J Phys Chem Ref Data. 1988;17:513-886. https://doi.org/10.1063/1.555805.

Changotra R, Guin JP, Khader SA, Varshney L, Dhir A. Electron beam induced degradation of ofloxacin in aqueous solution: kinetics removal mechanism and cytotoxicity assessment. Chem Eng J. 2019;356:973-84. https://doi.org/10.1016/j.cej.2018.08.156.

Dai Y, Zhao D, Qi Y. Sono-desulfurization oxidation reactivities of FCC diesel fuel in metal ion $/ \mathrm{H}_{2} \mathrm{O}_{2}$ systems. Ultrason Sonochem. 2011;18:264-8. https://doi.org/10.1016/j.ultsonch.2010.06.006.

de Luna MDG, Samaniego ML, Ong DC, Wan MW, Lu MC. Kinetics of sulfur removal in high shear mixing-assisted oxidative-adsorptive desulfurization of diesel. J Clean Prod. 2018;178:468-75. https://doi.org/10.1016/j.jclepro.2018.01.049.

Deshpande A, Bassi A, Prakash A. Ultrasound-assisted, base-catalyzed oxidation of 4,6-dimethyldibenzothiophene in a biphasic diesel-acetonitrile system. Energy Fuel. 2005;19:28-34. https ://doi.org/10.1021/ef0340965.

Farzin-Nejad N, Miran-Beigi AA. Efficient desulfurization of gasoline fuel using ionic liquid extraction as a complementary process to adsorptive desulfurization. Pet Sci. 2015;12:330-9. https://doi. org/10.1007/s12182-015-0020-2.

Flores R, Rodas A, Uscanga D, Dominguez CA. Desulfurization of flue gases using materials based on $\mathrm{Ca}(\mathrm{OH})_{2}$ supported on clays. Asian J Chem Sci. 2018a;4:1-12. https://doi.org/10.9734/AJOCS /2018/42236.

Flores R, Rodas A, Dominguez CA, Uscanga D. Development of $\mathrm{CuO}$ sorbent materials supported on metal oxides and clays applied to flue gas desulfurization. World J Eng Res Technol. 2018b;4:105-16.

Giannakis S, Liu S, Carratalà A, Rtimi S, Bensimon M, Pulgarin C. Effect of $\mathrm{Fe}(\mathrm{II}) / \mathrm{Fe}$ (III) species, $\mathrm{pH}$, irradiance and bacterial presence on viral inactivation in wastewater by the photo-Fenton process: kinetic modeling and mechanistic interpretation. App Catal B Environ. 2017;204:156-66. https://doi.org/10.1016/j.apcat b.2016.11.034.

Hao D, You W, Liu P, Li C, Wu Q, Lü H. Deep desulfurization of diesel by selective oxidation using amphiphilic paradodecatungstate catalyst. Phosphorus, Sulfur Silicon Relat Elem. 2016;191:30-4. https://doi.org/10.1080/10426507.2015.1073276.

Jiang W, Zhu W, Chang Y, Chao Y, Yin S, Liu H, et al. Ionic liquid extraction and catalytic oxidative desulfurization of fuels using dialkylpiperidinium tetrachloroferrates catalysts. Chem Eng J. 2014;250:48-54. https://doi.org/10.1016/j.cej.2014.03.074.

Jiang W, Jia H, Zheng Z, Zhu L, Dong L, Liu W et al. Catalytic oxidative desulfurization of fuels in acidic deep eutectic solvents with $\left[\left(\mathrm{C}_{6} \mathrm{H}_{13}\right)_{3} \mathrm{P}\left(\mathrm{C}_{14} \mathrm{H}_{29}\right)\right]_{3} \mathrm{PMo}_{12} \mathrm{O}_{40}$ as a catalyst. Pet Sci. 2018;15:841-8. https://doi.org/10.1007/s12182-018-0263-9.

Julião D, Gomes AC, Pillinger M, Cunha-Silva L, de Castro B, Gonçalves IS et al. Desulfurization of model diesel by extraction/oxidation using a zinc-substituted polyoxometalate as catalyst under homogeneous and heterogeneous (MIL-101 (Cr) encapsulated) conditions. Fuel Process Technol. 2015;131:78-86. https://doi. org/10.1016/j.fuproc.2014.10.030.

Kairbekov ZK, Myltykbaeva ZK, Muktaly D, Nysanova B, Anisimo AV, Akopya AV. Peroxide oxidative desulfurization of a diesel fuel. Theor Found Chem Eng. 2018;52:677-80. https://doi. org/10.1134/S0040579518040139.

Li H, Zhu W, Zhu S, Xia J, Chang Y, Jiang W et al. The selectivity for sulfur removal from oils: an insight from conceptual density functional theory. AIChE J. 2016;62:2087-100. https://doi. org/10.1002/aic.15161.

Liu S, Wang B, Cui B, Sun L. Deep desulfurization of diesel oil oxidized by $\mathrm{Fe}(\mathrm{VI})$ systems. Fuel. 2008;87:422-8. https://doi. org/10.1016/j.fuel.2007.05.029.

Lü H, Wang S, Deng C, Ren W, Guo B. Oxidative desulfurization of model diesel via dual activation by a protic ionic liquid. J Hazard Mater. 2014a;279:220-5. https://doi.org/10.1016/j.jhazm at.2014.07.005.

Lü H, Deng C, Ren W, Yang X. Oxidative desulfurization of model diesel using $\left[\left(\mathrm{C}_{4} \mathrm{H}_{9}\right)_{4} \mathrm{~N}\right] 6 \mathrm{Mo}_{7} \mathrm{O}_{24}$ as a catalyst in ionic liquids. Fuel Process Technol. 2014b;119:87-91. https://doi.org/10.1016/j. fuproc.2013.10.023.

Margeta D, Sertić-Bionda K, Foglar L. Ultrasound assisted oxidative desulfurization of model diesel fuel. Appl Acoust. 2016a;103:202-6. https://doi.org/10.1016/j.apacoust.2015.07.004.

Margeta D, Grčić I, Papić S, Sertić-Bionda K, Foglar L. Impact of ultrasound application on oxidative desulphurization of diesel fuel and on treatment of resulting wastewater. Environ Technol. 2016b;37:293-9. https://doi.org/10.1080/09593330.2015.10688 70.

Rafiee E, Sahraei S, Moradi GR. Extractive oxidative desulfurization of model oil/crude oil using KSF montmorillonite-supported 12-tungstophosphoric acid. Pet Sci. 2016;13:760-9. https://doi. org/10.1007/s12182-016-0127-0. 
Safa M, Mokhtarani B, Mortaheb HR, Tabar Heidar K, Sharifi A, Mirzaei M. Oxidative desulfurization of diesel fuel using a Brønsted acidic ionic liquid supported on silica gel. Energy Fuels. 2017;2017(31):10196-205. https://doi.org/10.1021/acs.energ yfuels.6b03505

Sun H, Wu P, He J, Liu M, Zhu L, Zhu F et al. Fabrication of oxygendefective tungsten oxide nanorods for deep oxidative desulfurization of fuel. Pet Sci. 2018;15:849-56. https://doi.org/10.1007/ s12182-018-0265-7.

Tomskii IS, Vishnetskaya MV, Vakhrushin PA, Tomskaya LA. Oxidative desulfurization of straight-run diesel fraction on vanadiummolybdenum catalysts. Pet Chem. 2017;57:908-13. https://doi. org/10.1134/S0965544117100188.

Viollier E, Inglett PW, Hunter K, Roychoudhury AN, Van Cappellen P. The ferrozine method revisited: $\mathrm{Fe}(\mathrm{II}) / \mathrm{Fe}(\mathrm{III})$ determination in natural waters. Appl Geochem. 2000;15:785-90. https://doi. org/10.1016/S0883-2927(99)00097-9.

Wu L, Ye F, Lei D, Miao G, Liu B, Li Z et al. Regeneration of AgXO@ SBA-15 for reactive adsorptive desulfurization of fuel. Pet Sci. 2018;15:857-69. https://doi.org/10.1007/s12182-018-0264-8.
Yang H, Jiang B, Sun Y, Zhang L, Huang Z, Sun Z et al. Heterogeneous oxidative desulfurization of diesel fuel catalyzed by mesoporous polyoxometallate-based polymeric hybrid. J Hazard Mater. 2017;333:63-72. https://doi.org/10.1016/j.jhazmat.2017.03.017.

Yu X, Zhao M, Han P, Lu X. Ultrasound assisted catalytic oxidative desulfurization of diesel oil using $\mathrm{CdO}$ nanoparticles. Petrol Sci Technol. 2018a;36:1158-63. https://doi.org/10.1080/10916 466.2018.1465961.

Yu Z, Wang D, Xun S, He M, Ma R, Jiang W et al. Amorphous $\mathrm{TiO}_{2}$-supported Keggin-type ionic liquid catalyst catalytic oxidation of dibenzothiophene in diesel. Petrol Sci. 2018b;15:870-81. https://doi.org/10.1007/s12182-018-0268-4.

Zhu W, Dai B, Wu P, Chao Y, Xiong J, Xun S et al. Graphene-analogue hexagonal BN supported with tungsten-based ionic liquid for oxidative desulfurization of fuels. ACS Sustainable Chem Eng. 2015;3:186-94. https://doi.org/10.1021/sc5006928. 